\title{
Chapter 4 \\ Estimation of Biomass Water Equivalent via the Cosmic Ray Neutron Sensor
}

\author{
T. E. Franz, A. Wahbi, and W. Avery
}

\subsection{The Role of Biomass in the CRNS Calibration}

The CRNS functions at its most fundamental level as a detector of the hydrogen within its area of influence (circle of radius $\sim 250 \mathrm{~m}$ ). As such, hydrogen other than that within the water molecules in the soil is detected. A series of calibration equations have been developed to quantify and eliminate these sources of hydrogen so that the signal of soil moisture can be isolated [1-6]. McJannet et al. [7] demonstrated that soil moisture is the largest contributor of hydrogen to the signal of the CRNS with growing biomass contributing only slightly. These data show that in an agricultural environment, the most significant source of error comes in the form of soil lattice water (i.e., hydrogen molecules integrated into mineral structures and bound water between mineral grains not released at oven drying temperatures of $105^{\circ} \mathrm{C}$ for $24 \mathrm{~h}$ ) and from water vapor in the atmosphere. Despite this, growing biomass if left unquantified remains a source of uncertainty that must be addressed, partly in fast-growing agricultural crops. Much of the current and past research into the CRNS in agricultural environments focuses on its use as a sensor of soil moisture. However, there have also been investigations into its use as a tool for estimating growing crop biomass itself [8,

T. E. Franz $(\bowtie)$

School of Natural Resources, University of Nebraska-Lincoln, Lincoln, NE, USA e-mail: Trenton.franz@unl.edu

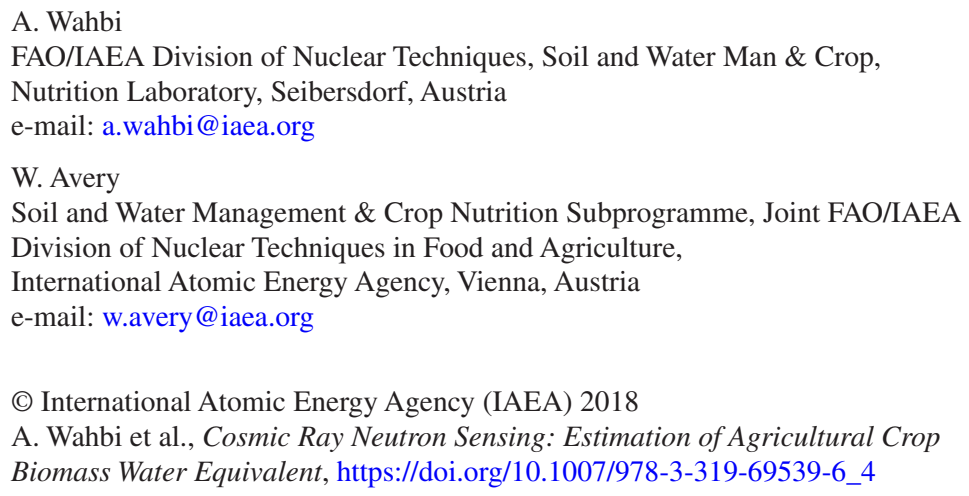


9]. Note that the biomass signal is fairly small and challenging to remove from the soil moisture signal and inherent noise in the neutron counts. This requires use of large detectors (i.e., high count rates on the order of 5000 to 10,000 to minimize uncertainty) and certain biomass detection limits (i.e., on the order of $0.5 \mathrm{~kg} / \mathrm{m}^{2}$ ). Nevertheless the technique is theoretically sound [6] and an area of active research.

\subsection{Relationship Between Neutrons and Crop Biomass}

During the CRNS calibration process, the variable " $\mathrm{N}_{0}$ " is calculated for each field site in a particular experiment. $\mathrm{N}_{0}$ is a theoretical count rate of neutrons detected by the CRNS in an environment devoid of vegetation with dry silica soils present within the instrument footprint. The role of this variable in the calibration function is given by Desilets et al. [1]. Hawdon et al. [8] postulated on the use of the CRNS as a tool for the spatial mapping of biomass rather than soil moisture. The authors explain that once all sources of environmental hydrogen have been taken into account, the $\mathrm{N}_{0}$ should be the same when calculated for all study areas. However, they had not yet taken into account the effect of growing maize biomass. As such, the authors determined in their study that $\sim 80 \%$ of the variation in $\mathrm{N}_{0}$ they observed was due to this biomass after all other sources of hydrogen had been quantified. Noted that for short grasslands, cereal crops, and legume crops with BWE changes of $<2 \mathrm{~kg} / \mathrm{m}^{2}$ that $\mathrm{N}_{0}$ will not be greatly affected. For use in maize, sugarcane, bamboo, and soybean, $\mathrm{N}_{0}$ should be corrected for changes in BWE.

Franz et al. [4] determined a linear relationship between biomass water equivalent (BWE) and $\mathrm{N}_{0}$ using a mobile CRNS within agricultural maize fields in central Nebraska, USA. Franz et al. [4] found a $1 \%$ decline in $\mathrm{N}_{0}$ for every $1 \mathrm{~kg} / \mathrm{m}^{2}$ of BWE ( $\mathrm{R}^{2}$ of 0.51 ). In addition to this, Baatz et al. [9] demonstrated a similar relationship (i.e., $1 \%$ drop in $\mathrm{N}_{0}$ for $1 \mathrm{~kg} / \mathrm{m}^{2}$ of biomass) between aboveground biomass and the CRNS counting rate $\mathrm{N}_{0}$.

The procedures involved with determining aboveground crop biomass via the CRNS alone would involve predetermined experiments similar to those discussed previously. To be more specific, datasets would have to be made at specific study sites for any particular research project, between the CRNS $\mathrm{N}_{0}$ counting rate and biomass water equivalent as determined via destructive sampling or remote sensing, and calculated via Eq. 2.1. Once multiple datasets have been made, a statistical relationship can be determined between the two variables; $\mathrm{N}_{0}$ can be used as a predictive variable for aboveground crop biomass (assuming different study sites have similar crops and other environmental characteristics).

\subsection{Direct Relationship Between Neutrons and Biomass}

Preliminary theoretical and experimental work using multiple detector energies (bare, cadmium-shielded, and plastic-shielded detectors $[10,11])$ is encouraging for detecting and separating multiple hydrogen signals, like soil moisture and biomass. Typically, 

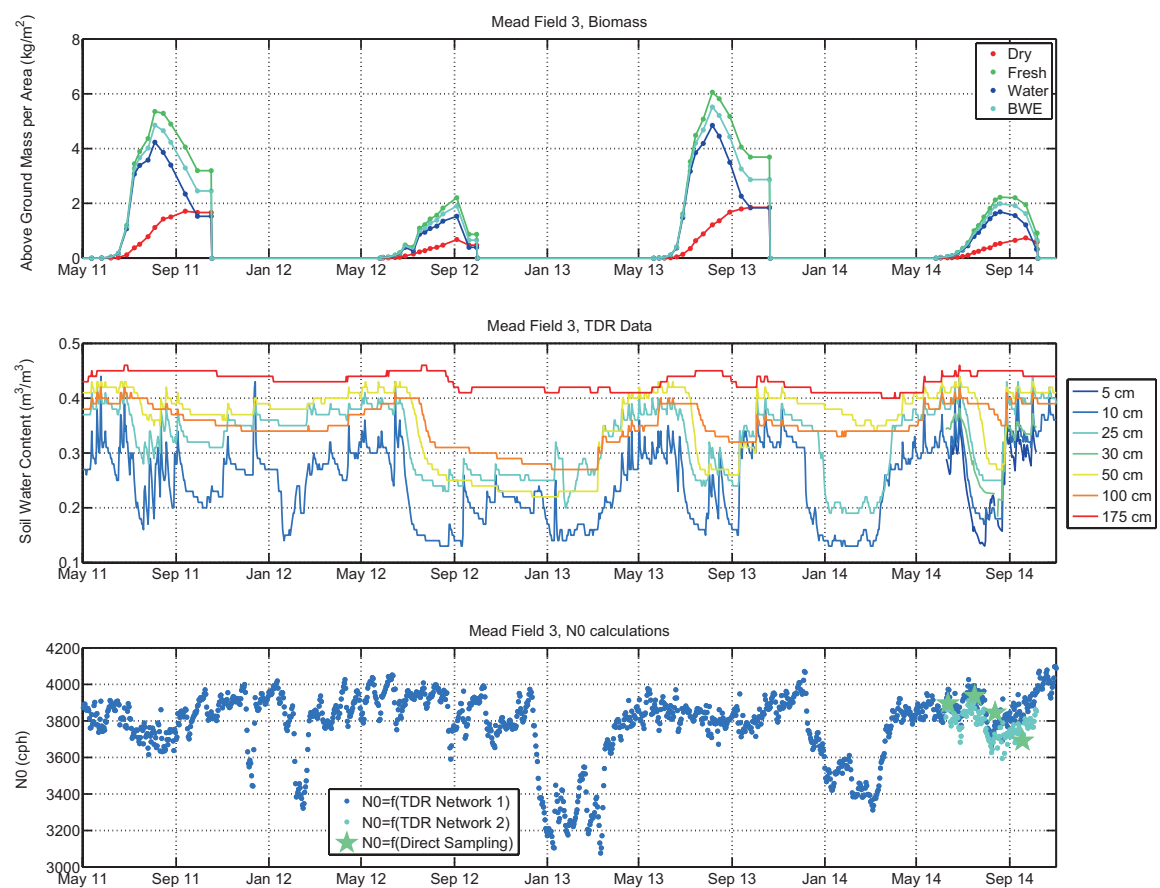

Fig. 4.1 (Top) Time series of daily dry, fresh, water, and biomass water equivalent biomass for a rotational maize and soybean field in Eastern Nebraska, USA [5]. Point values indicate direct sample collection dates. A linear interpolation (line) was used to create a daily dataset. (Middle) time series of spatially averaged TDR values from network 1 (5 locations) and network 2 (4 locations) for various depths. (Bottom) time series of daily $\mathrm{N}_{0}$ values calculated from TDR network 1 , TDR network 2, and direct sampling in 2014 using soil water content data between 0 and $30 \mathrm{~cm}$ (see [4] for details). Note that the ground may be covered in snow between December and March at the study site

most CRNS study sites have included a bare and plastic-shielded detector by default. The ratio of bare counts to plastic-shielded counts (aka thermal to fast ratio) has been shown to be correlated to direct estimates of BWE for a particular site [12].

Unpublished work by Franz shows promising results from Nebraska for maize and soybeans using relationships between $N_{0} / \mathrm{BWE}$ vs. bare to plastic count ratio vs. plastic count ratio. Figure 4.1 illustrates a daily time series of aboveground biomass, a soil water content monitoring network (TDR), and derived $N_{0}$ values. It is clear that having soil water content monitoring in the near surface $(\sim 5 \mathrm{~cm}$ depth) or direct sampling improves the relationship. Figure 4.2 illustrates the relationship between $N_{0}$, moderated counts, and bare to moderated ratio. Figure 4.3 illustrates the relationship between BWE, moderated counts, and bare to moderated ratio. Again a linear (i.e., a plane) relationship manifests in the data. This indicates that combining repeat-destructive sampling of BWE over the course of a growing season with bare and moderated neutron counts can be used to directly estimate BWE changes through time. An appropriate suggestion is that a minimum of 5-7 destructive sampling periods are used to estimate the coefficients describing the equation of a plane: 


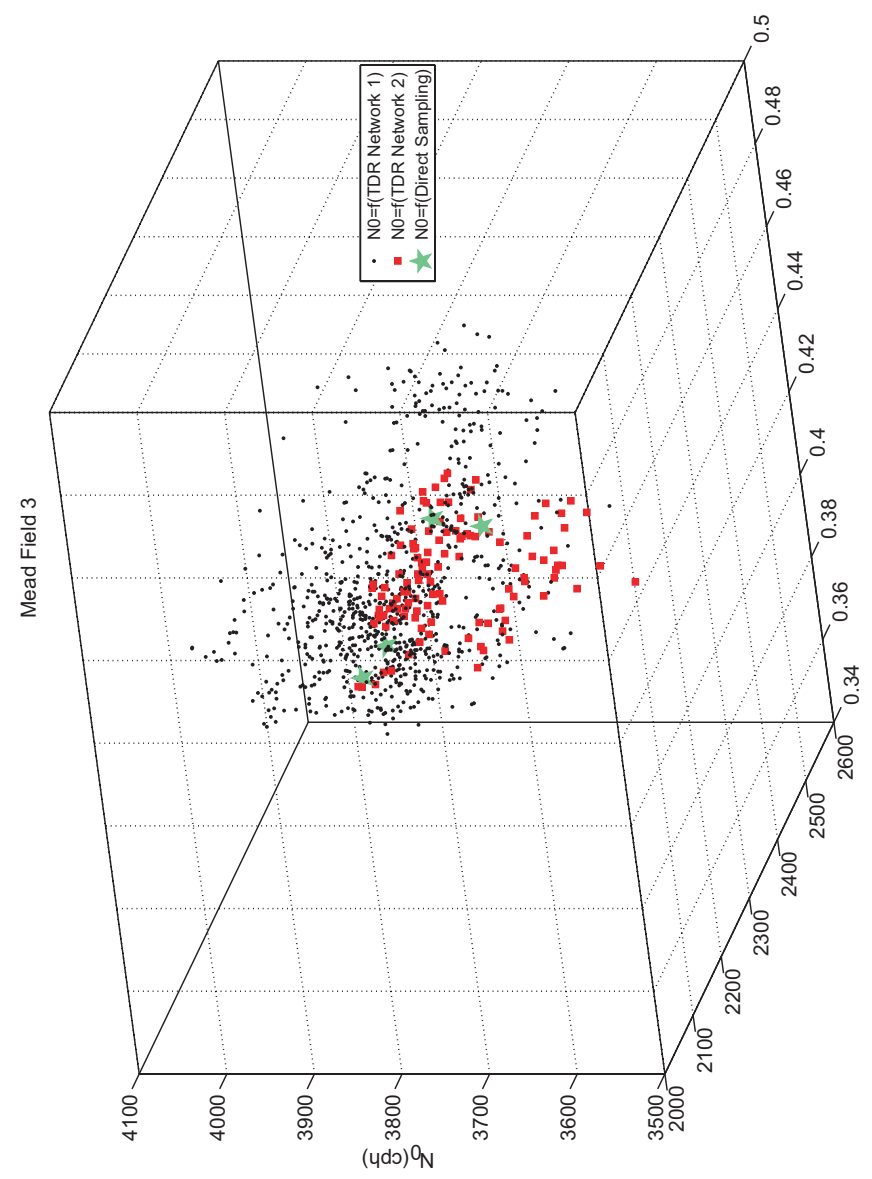

흘

그음

6

II

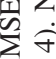

事 11

क'

ป :

II

$\approx$

- II

늠 桴

$\sum_{0}^{\infty}$

을

ప艹

$\circ \stackrel{2}{\mathscr{2}}$

苞 寸

유

픈..$\Xi$

ఫิ

ఏ

오

象

चี प्ठ

$\dot{s}=$

ర్

훈

ఏ II

$\dot{\mathrm{s}} \mathrm{Z}$

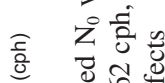

¿ छ

需 娄

규 है

准

$0=0$

纪完

ฮี

$\frac{\bar{t}}{0} \approx \frac{n}{2}$

帘

들

중

总昆

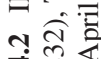

$+\infty$

曷 11 


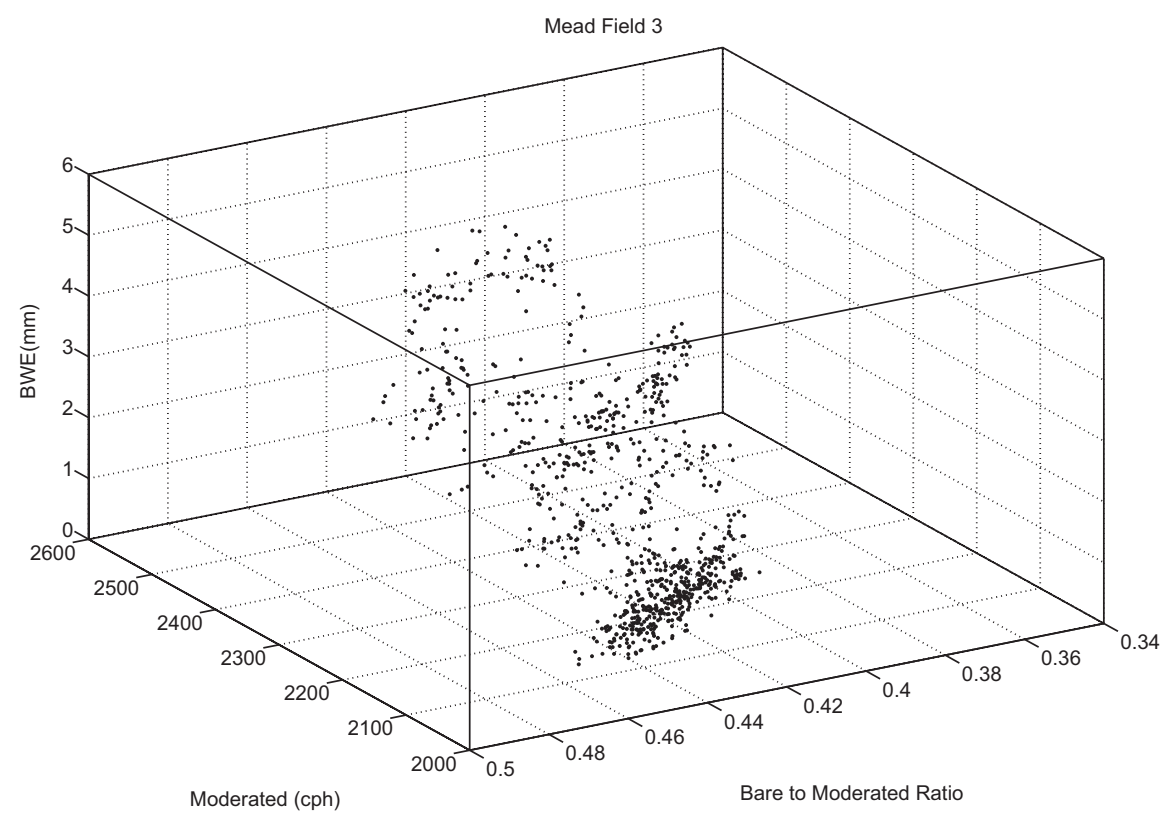

Fig. 4.3 Relationship between observed daily average moderated neutron counts, bare to moderated ratio, and BWE. Regression indicates a plane fits the data well $\left(\mathrm{R}^{2}=0.8476, \mathrm{RMSE}=0.631 \mathrm{~kg} /\right.$ $\mathrm{m}^{2}, \mathrm{~N}=832$ ). The relationship to biomass appears to be linear for soybean and corn with BWE less than $6 \mathrm{~kg} / \mathrm{m}^{2}$

$$
B W E=a+b^{*} M+c^{*} B M
$$

where $a, b$, and $c$ are locally defined coefficients, $M$ is corrected moderated neutron counts, and $B M$ is the ratio of raw bare and moderated neutron counts (no corrections are needed for the ratio). Note that the signal to noise ratio is small and suggests high count rates be used for $M$ and $B M(>20,000)$. This can be achieved by using daily to multiday averages or multiple detectors. Note that given the dependence of detected plastic-shielded neutrons and bare neutrons (i.e., thermal neutrons are generated from local fast neutrons), local factors may affect this relationship. Figures 4.4 and 4.5 illustrate the derived daily BWE for rainfed maize in 2011 and rainfed soybean in 2014. Note that the derived BWE is very similar in shape (unscaled) to seasonal crop coefficient $(\mathrm{kc})$ relationships [13] widely used in agricultural practice. Accurate determination of daily crop coefficient has large potential practical use in irrigation scheduling and calibration and validation of remote sensing products. The combination of an accurate soil moisture and crop coefficient makes CRNS an exciting tool to combine with crop simulation models like FAO AquaCrop, for real-time applications of water management and yield forecast. Lastly, note that techniques of energy separation using a third cadmium-shielded detector may be necessary, in addition to quantifying the differences in background hydrogen (i.e., lattice water) that may affect the $a, b$, and $c$ coefficients in Eq. 4.1. The area of multi-signal hydrogen separation using CRNS remains an exciting and challenging research area. 

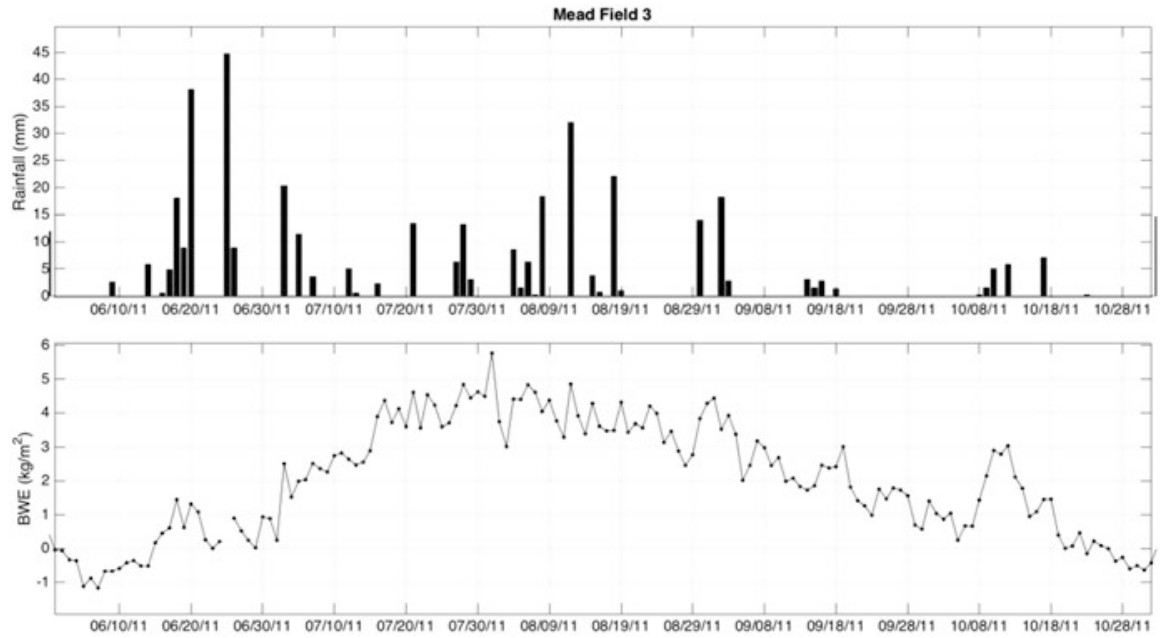

Fig. 4.4 Derived daily BWE for rainfed maize in Eastern Nebraska in 2011. Note the shape of BWE over the growing season is very similar to crop coefficients (scale from $\sim 0$ to 1 ) widely used in agricultural practice
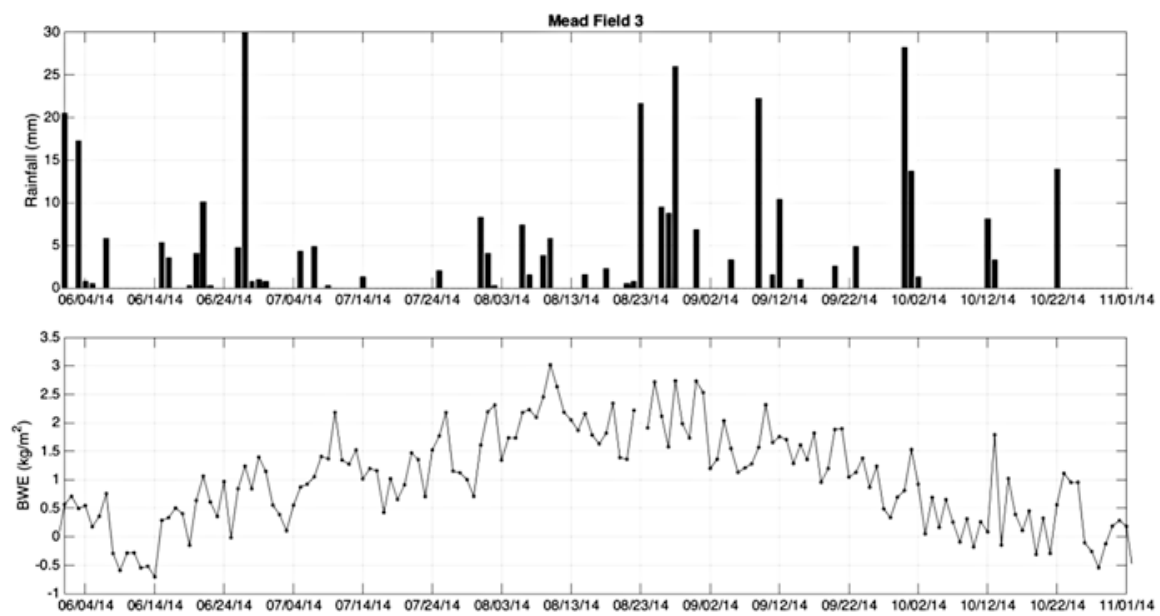

Fig. 4.5 Derived daily BWE for rainfed soybean in Eastern Nebraska in 2014. Note the shape of BWE over the growing season is very similar to crop coefficients (scale from $\sim 0$ to 1 )

\subsection{Conclusions}

The presence of agricultural biomass within the footprint of the CRNS contributes its hydrogen to the signal of the sensor. As such, a calibration aimed in part to quantify the hydrogen in said biomass as a function of its water equivalent (BWE, Eq. 2.1 ) is employed. It is possible with sufficient comparisons of the CRNS counting 
rate " $\mathrm{N}_{0}$ " and BWE for the CRNS to be used as a tool for mapping biomass within agricultural environments. Preliminary and theoretical works indicate an opportunity for multi-detector CRNS to separate and isolate multiple hydrogen sources simultaneously. Furthermore, note that the derived BWE is very similar in shape (unscaled) to seasonal crop coefficient relationships widely used in agricultural practice. This has large potential practical uses in irrigation scheduling, calibration and validation of remote sensing products, and use in simulation models like FAO AquaCrop. It is important to consider this application due to the inherent advantages the CRNS possesses in regard to mapping spatial soil moisture, in particular its large spatial footprint and noninvasive and nondestructive nature.

This publication illustrates three techniques for the estimation of crop biomass for use in the CRNS calibration function: destructive in situ sampling, remote sensing of the land surface via satellites, and the sensing of biomass via the CRNS itself. These three methods give environmental scientists additional tools for investigations into agricultural ecosystems and human use of the land and water. Ultimately, this work is intended to serve as a supplemental guideline for the use of the CRNS around the world.

\section{References}

1. Desilets D, Zreda M, Ferre TPA (2010) Nature's neutron probe: land surface hydrology at an elusive scale with cosmic rays. Water Resour Res 56:W11505

2. Zreda M, Schuttleworth WJ, Zeng X, Zweck C, Desilets D, Franz T, Rosolem R (2012) COSMOS: the cosmic ray soil moisture observing system. Hydrol Earth Syst Sci 16:4079

3. Franz TE, Zreda M, Ferre PA, Rosolem R, Zweck C, Stillman S, Zeng X, Shutt WJ (2012) Measurement depth of the cosmic ray soil moisture probe affected by hydrogen from various sources. Water Resour Res 48:W08515

4. Franz TE, Wang T, Avery W, Finkenbiner C, Brocca L (2015) Combined analysis of soil moisture measurements from roving and fixed cosmic ray neutron probes for multiscale real-time monitoring. Geophys Res Lett 42:3389

5. Avery WA, Finkenbiner C, Franz TE, Wang T, Nguy-Robertson AL, Suyker A, Arkebauer T, Munoz-Arriola F (2016) Incorporation of globally available datasets into the roving cosmic ray neutron probe method for estimating field-scale soil water content. Hydrol Earth Syst Sci 20:3859

6. Franz TE, Zreda M, Rosolem R, Hornbuckle BK, Irvin SL, Adams H, Kolb TE, Zweck C, Shuttleworth WJ (2013) Ecosystem scale measurements of biomass water using cosmic ray neutrons. Geophys Res Lett 40:3923

7. McJannet D, Franz TE, Hawdon A, Boadle D, Baker B, Almeida A, Silberstein R, Lambert T, Desilets D (2014) Field testing of the universal calibration function for determination of soil moisture with cosmic ray neutrons. Water Resour Res 50:5235

8. Hawdon A, McJannet D, Wallace J (2014) Calibration and correction procedures for cosmic ray neutron soil moisture probes located across Australia. Water Resour Res 50:5029

9. Baatz R, Bogena HR, Hendricks Franssen J, Huisman A, Montzka C, Vereecken H (2015) An empirical vegetation correction for soil water content quantification using cosmic ray probes. Water Resour Res 51:2030

10. Andreasen M, Jensen KH, Zreda M, Desilets D, Bogena H, Looms MC (2016) Modeling cosmic ray neutron field measurements. Water Resour Res 52:6451 
11. Andreasen M, Jensen KH, Desilets D, Zreda M, Bogena HR, Looms MC (2017) Cosmic-ray neutron transport at a forest field site: the sensitivity to various environmental conditions with focus on biomass and canopy interception. Hydrol Earth Syst Sci 21:1875

12. Tian ZC, Li ZZ, Liu G, LI BG, Ren TS (2016) Soil water content determination with cosmicray neutron sensor: correcting aboveground hydrogen effects with thermal/fast neutron ratio. J Hydrol 540:923

13. Allen RG, Pereira LS, Raes D, Smith M (1998) Crop Evapotranspiration: Guidelines for Computing Crop Water Requirements, FAO Irrigation and Drainage Paper 56. Food and Agriculture Organization of the United Nations, Rome

The opinions expressed in this chapter are those of the author(s) and do not necessarily reflect the views of the International Atomic Energy Agency (IAEA), its Board of Directors, or the countries they represent.

Open Access This chapter is licensed under the terms of the Creative Commons Attribution 3.0 IGO license (https://creativecommons.org/licenses/by/3.0/igo/), which permits use, sharing, adaptation, distribution and reproduction in any medium or format, as long as you give appropriate credit to the IAEA, provide a link to the Creative Commons license and indicate if changes were made.

Any dispute related to the use of the works of the IAEA that cannot be settled amicably shall be submitted to arbitration pursuant to the UNCITRAL rules. The use of the IAEA's name for any purpose other than for attribution, and the use of the IAEA's logo, shall be subject to a separate written license agreement between the IAEA and the user and is not authorized as part of this CC-IGO license. Note that the link provided above includes additional terms and conditions of the license.

The images or other third party material in this chapter are included in the chapter's Creative Commons license, unless indicated otherwise in a credit line to the material. If material is not included in the chapter's Creative Commons license and your intended use is not permitted by statutory regulation or exceeds the permitted use, you will need to obtain permission directly from the copyright holder.

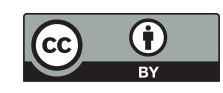

